\title{
THE EFFECT OF THINNING ON A YOUNG STAND OF WESTERN HEMLOCK
}

\section{By B. G. GRIFFITH ${ }^{1}$}

Braham G. Griffith received his B.A. degree with honors in Botany and Zoology from the University of British Columbia in 1926 and his M.A. degree from the same institution in 1928. In 1930 he received his M.F. degree from Harvard University and his Ph.D. from the University of Washington in 1937.

From 1926 to 1936 he was employed with the B.C. Forest Service, Research Division. In 1937 he joined the teaching staff of the University of British Columbia as an Instructor in the Departments of Botany and Forestry and at present is Associate Professor in the Faculty of Forestry.

Dr. Griffith has long been active in C.I.F. affairs having joined the Institute in 1930. At present Dr. Griffith is Chairman of the Membership Committee. He is a Director of the British Columbia Branch of the Canadian Forestry Association and has been Chairman of the Junior Forest Wardens Committee for a number of years. He has been a member of the Association of British Columbia Registered Foresters since 1947.

\section{PART I}

Comparison of Growth in the Thinned and Natural Stand

In the spring of 1950 a small area of a young uneven-aged stand of western hemlock, Tsuga heterophylla (Raf.) Sarg., was thinned on the Research Forest of the University of British Columbia. This forest is situated 35 miles east of Vancouver near the Village of Haney.

The study area was logged and burned in 1928 and subsequently it seeded in naturally, mainly to western hemlock, from a fringe of mature timber along the western boundary. The area is at an elevation of 1200 feet and has a site index of 110 feet at 100 years based on the average age and height of the dominant and codominant hemlock trees. The exposure is south-easterly, and the slope averages 15 per cent. The soil is a stony, sandy loam, with an average depth of 30 inches.

Although the stand was classified as pure western hemlock, it did contain a small admixture of Douglas fir, Pseudotsuga taxifolia (Poir.) Brit., and western red cedar, Thuja plicata Donn. The trees varied in age from 8 to 22 years in 1950 and averaged 18.2 years. The stand averaged 4,770 trees per acre with an average diameter of 2.02 inches, and an average height of 21.85 feet for the dominant and codominant hemlock trees.

Method of Study

A portion of the stand was thinned in 1950 to a uniform spacing of about 6 feet by 6 feet of dominant and codominant trees. Five rectangular plots, each 0.016 acres in size, were established prior to thinning. A control plot was established in the untreated part of the stand. On each plot all trees 1.00 inch

\footnotetext{
${ }^{1}$ Associate Professor, Faculty of Forestry, University of British Columbia Research Paper No. 24,
} Faculty of Forestry, University of B.C. Submitted for publication September 10, 1958. 
in d.b.h. and larger were recorded by species, diameter, and height. A record was kept of all trees removed in the thinning operation. The plots were remeasured at the end of the growing season in 1952 and again in 1957, that is, after 3 and 8 years of growth.

Table 1 gives the stand data for the control and the averages for the 5 thinned plots both before and after thinning in 1950. The control plot contained 76 trees and had a total basal area of 1.9295 square feet and an average diameter of 1.98 inches. The average height of the dominant and codominant hemlock trees was 22.0 feet. The thinned plots, prior to thinning, averaged 77.2 trees per plot and had a basal area of 1.9730 square feet and an average diameter of 2.03 inches. The average height of the dominant and codominant hemlock trees was 21.70 feet. After thinning the number of trees per plot was reduced to 19.6 and the basal area to 0.9129 square feet. The average diameter was increased to 2.73 inches, but the average height of the hemlock trees remained unchanged.

\section{Results}

Table 2 gives the stand data for the dominant and codominant trees of the control plot and the averages for the 5 thinned plots at the time of thinning and 3 and 8 growing seasons after thinning. There was no mortality for the first 5 years after thinning, but a few trees were killed in the winter of 1955 as the result of a severe snow storm. Total mortality on the control plot from 1950 to 1957 was 17 trees, but except for a few dominant and codominant

TABLE 1

Stand Data for the Control Plot and Averages for the Five Thinned Plots Before and After Thinning in 1950. Site IndeX 110.

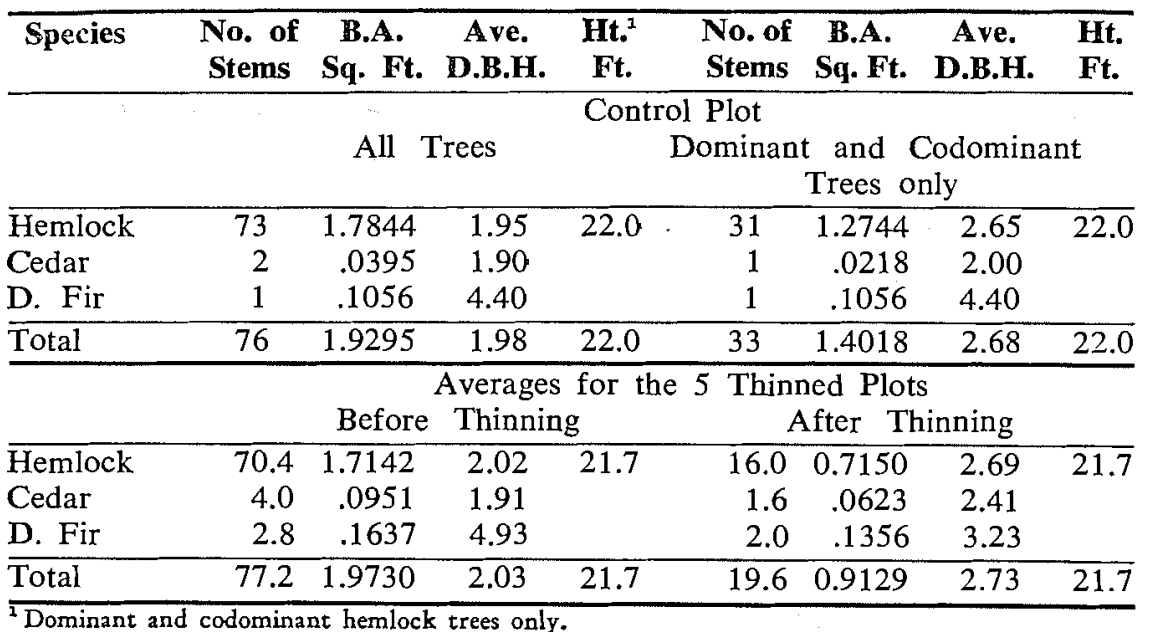




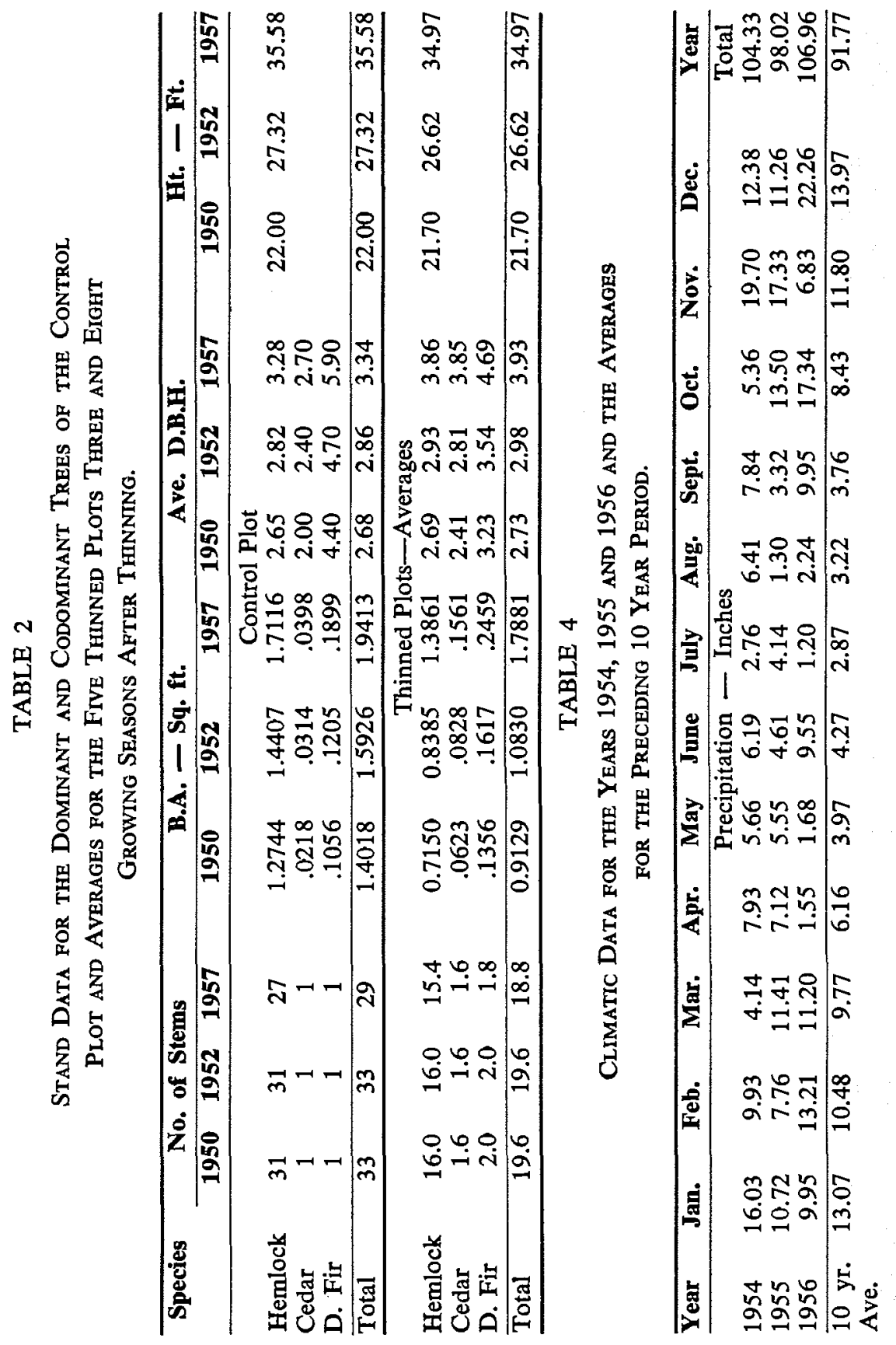




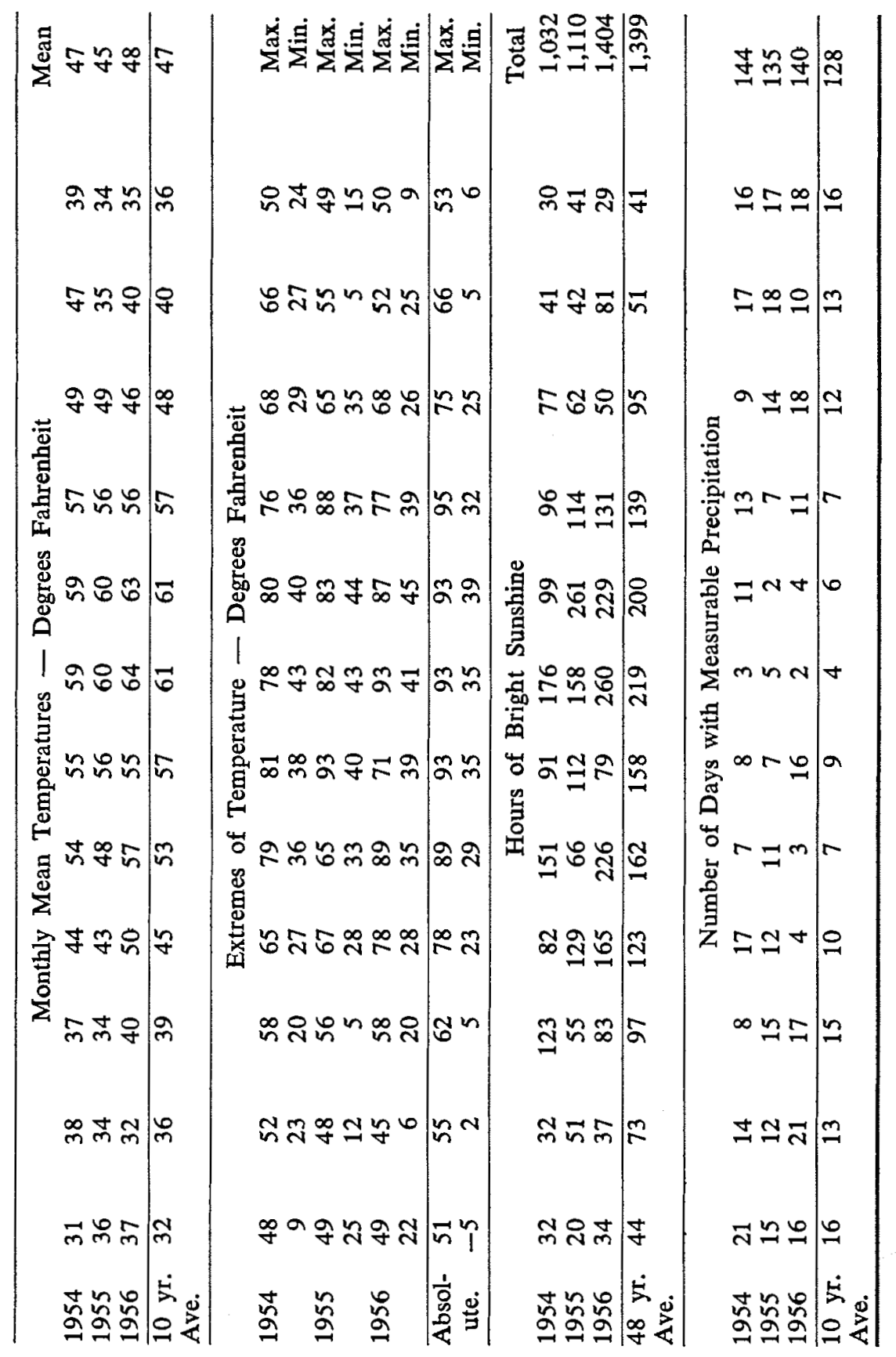


trees killed in 1955 by snow break, it consisted of intermediate and suppressed trees.

Basal area on the control plot increased from 1.4018 square feet to 1.5926 square feet by the end of the 1952 growing season and to 1.9413 square feet by the end of 1957 . On the thinned plots the average increase was from 0.9129 square feet in 1950 to 1.0830 square feet in the fall of 1952 and to 1.7881 square feet in the fall of 1957. This represents a gain of 0.1701 and 0.7051 square feet for the two periods after thinning, respectively, as compared with an increase of 0.1908 and 0.3487 square feet for the control plot. Average diameter of the dominant and codominant trees on the control plot increased from 2.68 inches in the spring of 1950 to 2.86 inches in the fall of 1952, and to 3.34 inches in the fall of 1957 . For the thinned plots the average diameter increased from 2.73 inches to 2.98 inches, and to 3.93 inches, for the two periods respectively.

Growth in height following thinning was approximately the same on the control and the treated plots. The dominant and codominant hemlock trees on the control plot increased an average of 13.58 feet in height during the period 1950 to 1957 as compared with an average increase of 13.27 feet for the thinned trees.

TABLE 3

Average Annual Percentage Increases in Basal Area, Diameter, and Height Growth for the Dominant and Codominant Hemlock Trees of the Control and Thinned Plots for the Periods 1950-52, 1953-57, and 1950-57, Representing 3, 5, aND 8 Growing Seasons Respectively.

\begin{tabular}{cccc}
\hline & $\mathbf{1 9 5 0 - 5 2}$ & $\mathbf{1 9 5 3 - 5 7}$ & $\mathbf{1 9 5 0 - 5 7}$ \\
\cline { 2 - 3 } & & Per Cent & \\
\hline Basal Area per Plot & & & \\
in Square Feet & & 3.76 & 4.29 \\
$\quad$ Control & 4.35 & 13.06 & 11.73 \\
$\quad \begin{array}{c}\text { Thinned } \\
\text { Diameter per Tree }\end{array}$ & 5.76 & & \\
$\quad$ in Inches & & 3.26 & 2.96 \\
$\quad$ Control & 2.14 & 5.35 & \\
$\quad$ Thinned & 2.97 & & 7.44 \\
Height per Tree & & & 7.72 \\
in Feet & & 6.05 & 7.64 \\
$\quad$ Control & 8.02 & 6.27 & \\
$\quad$ Thinned & 7.56 & & \\
\hline
\end{tabular}

\section{Discussion}

As is shown in Table 3, thinning had a marked effect on the growth of a stand of western hemlock. For the first 3 years after treatment the thinned 
JUNE, 1959

stand grew only slightly faster than the untreated stand, but during the succeeding 5-year period, growth of the treated stand greatly exceeded that of the control. Basal area during this latter period increased at an average annual rate of 13.06 per cent for the thinned plots as compared with an average annual rate of 3.76 per cent for the control plot. For the same period the average annual increase in diameter was 5.35 per cent for the thinned plots and 3.26 per cent for the control plot. Thinning had no noticeable effect on height growth.

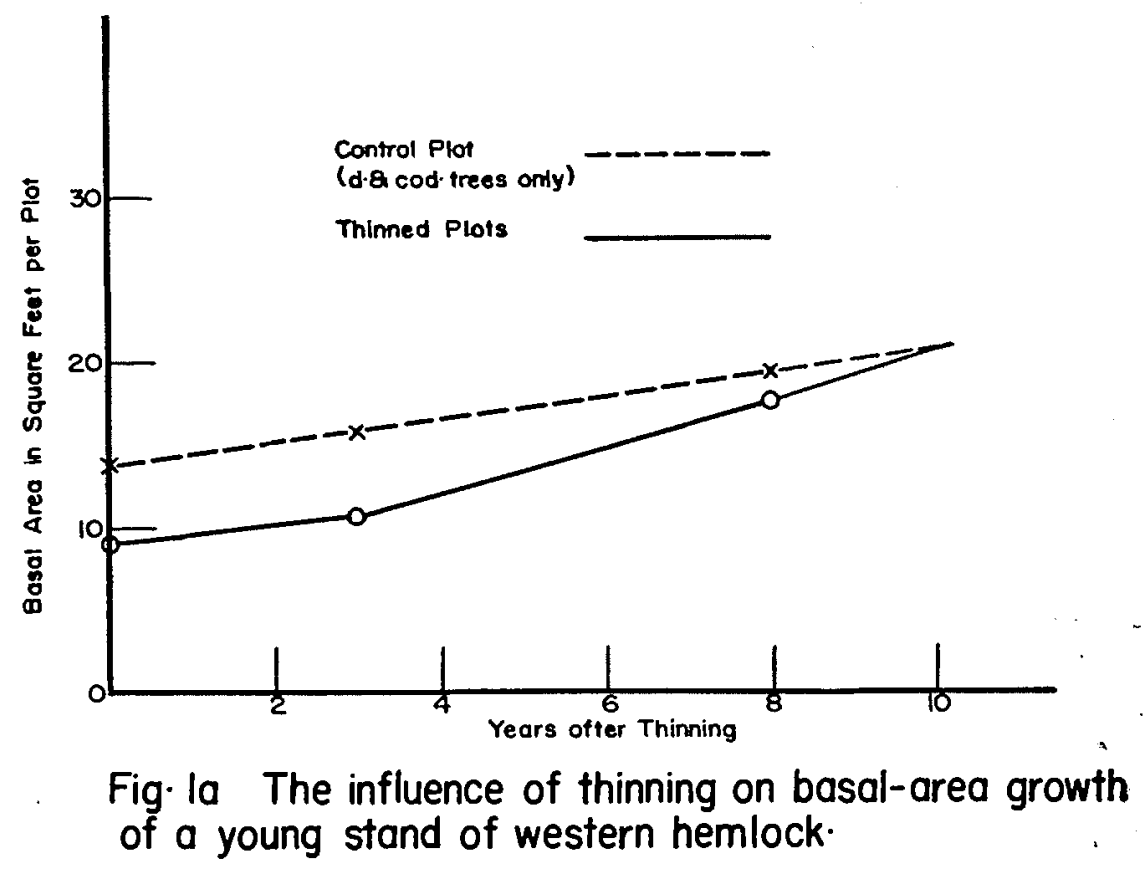

Figure 1a shows that total basal-area growth of the 16 hemlock trees on the average thinned plot was about equal to that of the 31 dominant and codominant hemlock trees on the control plot, and for the next 5 years greatly exceeded that of the control plot. If the present rates of growth continue for another 2 years, the total basal area of the average thinned plot will be the same as that of the control plot. That is, disregarding mortality, the 16 hemlock trees on the average thinned plot will have the same total basal area as the $\mathbf{3 1}$ hemlock trees on the control plot 10 years after thinning.

Summary

The 18-year-old stand of western hemlock showed a definite response to thinning. The response was particularly marked 3 years following the operation 
by which time the thinned trees increased in basal area at about 4 times the rate of the control trees. Total basal area of the thinned stand is expected to equal that of the dominant and codominant trees of the untreated stand 10 years after thinning. No mortality occurred in the thinned stand during the first 5 years following thinning.

\section{PART II}

Radial and Basal Area Growth of Individual Western Hemlock Trees in a Thinned and Unthinned Hemlock Stand

The pattern of growth of individual western hemlock trees in both thinned and unthinned stands was studied. Eighteen dominant and codominant trees within the thinned area and 9 trees in the unthinned area were prepared in April, 1954, for weekly dendrometer measurements by dial-gauge dendrometer. The average age of the sample trees was 23 years. The average diameter inside bark of the 18 trees on the thinned area was 4.48 inches, and of the 9 trees on the control area, 4.00 inches. Elevation of the study-area was 1200 feet. Rainfall and temperature records were obtained from a weather station maintained within the boundaries of the University Forest and situated 1.6 miles southeast of the study area at an elevation of 550 feet. Data on the number of hours of bright sunshine were obtained from the Dominion Meteorological weather station at Agassiz, 35 miles to the east and at an elevation of 130 feet. Dendrometer readings were recorded at approximately weekly intervals from April 15 to October 31 for the years 1954, 1955, and 1956. Weather data are summarized in Table 4.

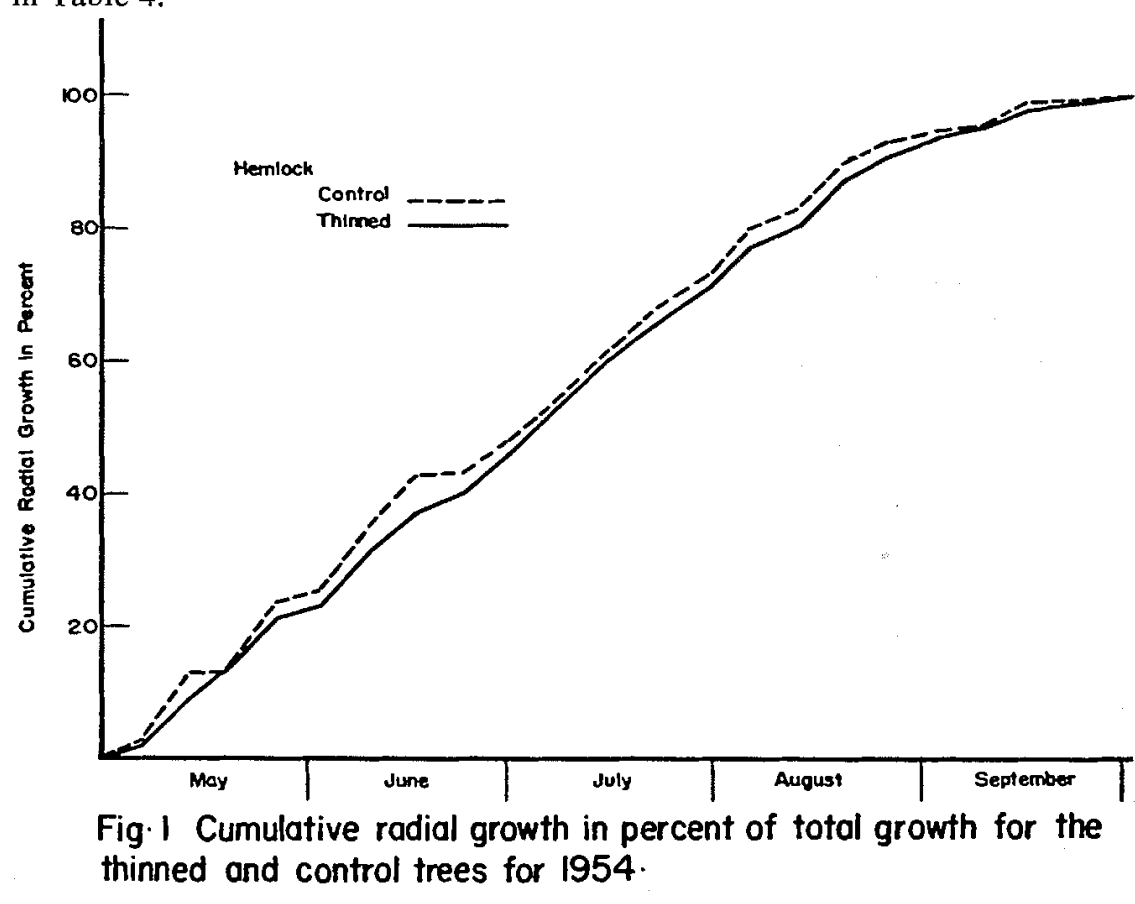




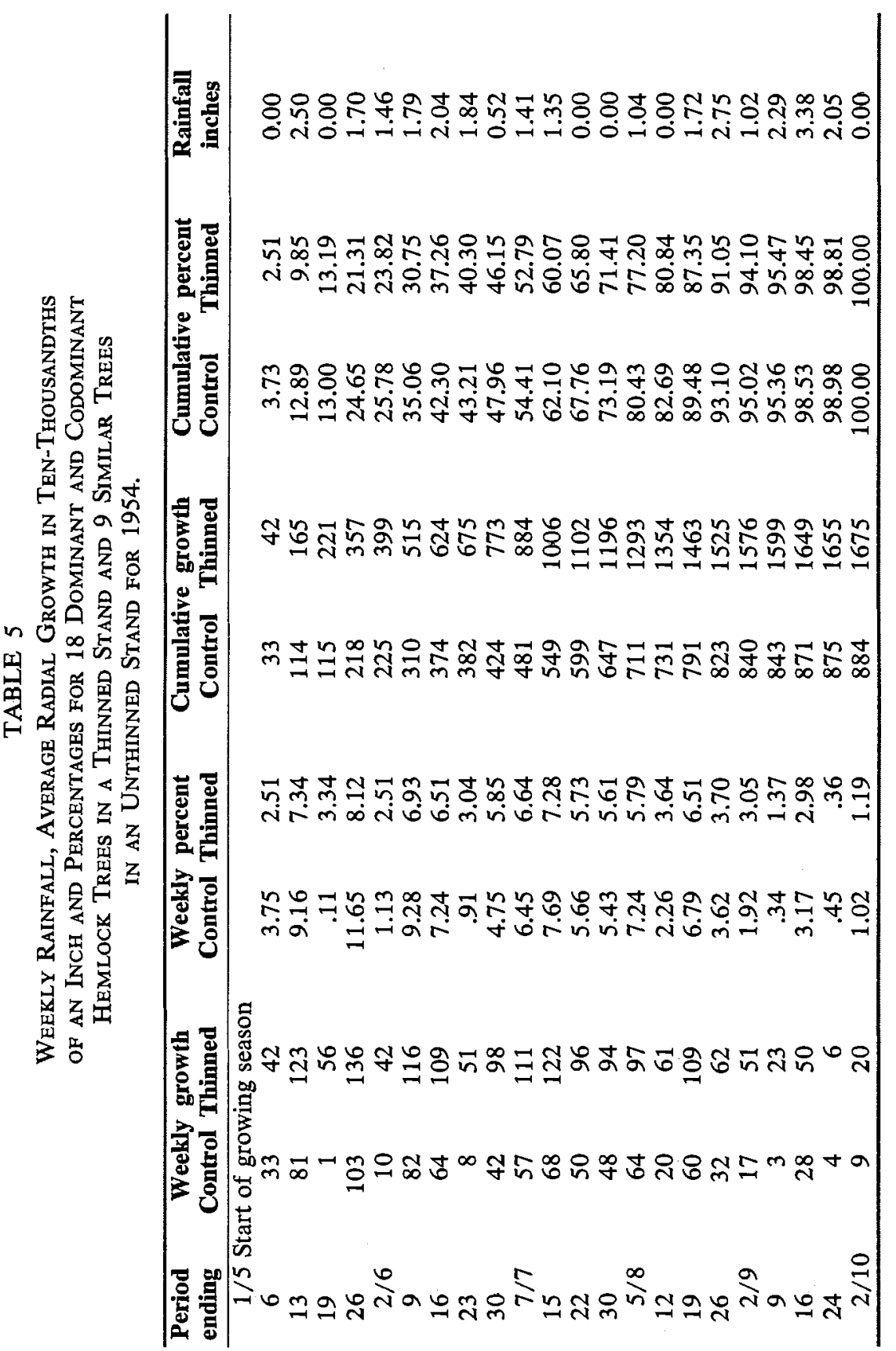




\section{Radial Growth}

\section{REsults}

1954. Table 5 gives the weekly radial growth for the trees on the control and thinned areas to the nearest ten-thousandths of an inch, weekly and cumulative percentage growth, and rainfall figures for the same periods. Dendrometer readings were commenced on April 15 and continued until October 26. No net growth occurred before May 1; after October 2 diameters fluctuated considerably but showed no permanent increase. These minor variations in diameter probably result from changes in the moisture content of the stems and from physiological modifications within the trees at the end of the growing period. Consequently, the period of diameter growth was considered to extend from May 1 to October 2; approximately 95 per cent of the total diameter growth had been completed by the end of August. Weekly radial growth was irregular throughout the growing season and appeared to follow no definite pattern. No significant relationship existed between weekly growth and rainfall or temperatures for the corresponding periods. Trees under control and thinned conditions exhibited similar irregular growth patterns in terms of percentage growth (Fig. 1) although the thinned trees increased in radius much more rapidly than the control trees -0.1675 inches in contrast to 0.0884 inches, respectively.

1955. Radial growth commenced about May 1 and terminated by about September 30 . Ninety-four per cent of the total growth had occurred by August

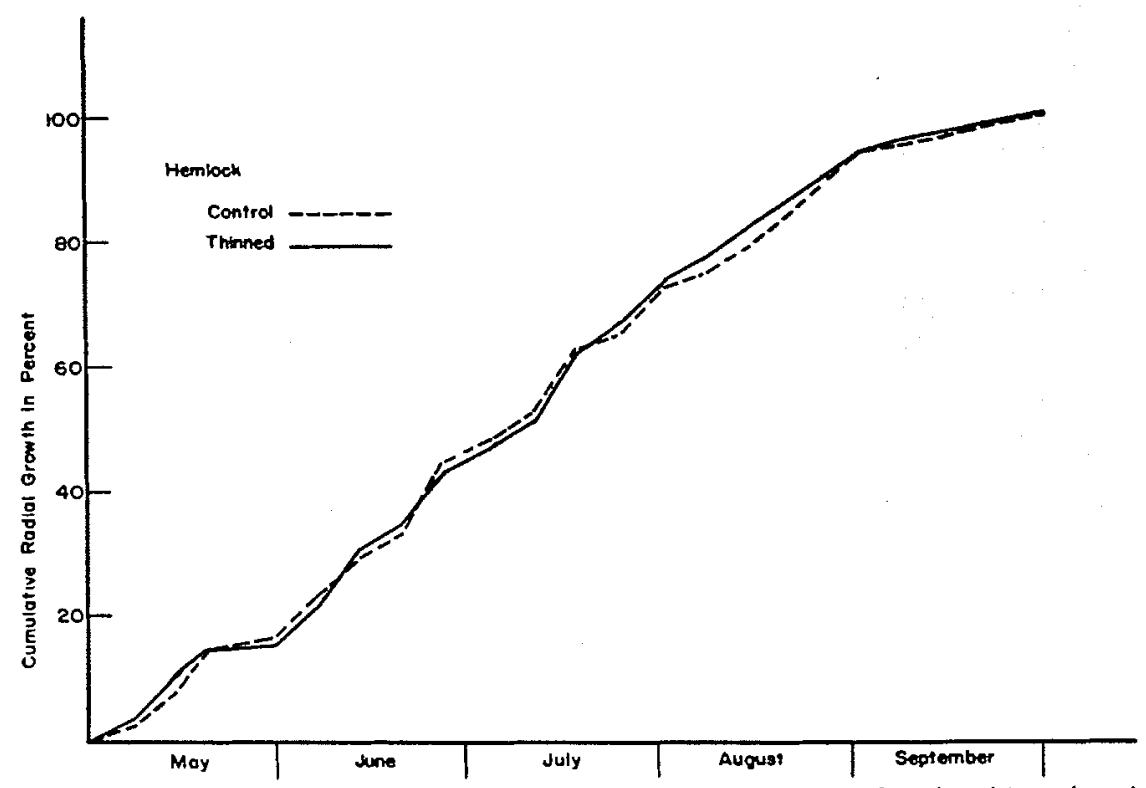

Fig. 2 Cumulative radial growth in percent of total growth for the thinned and control trees for 1955 . 
JUNE, 1959

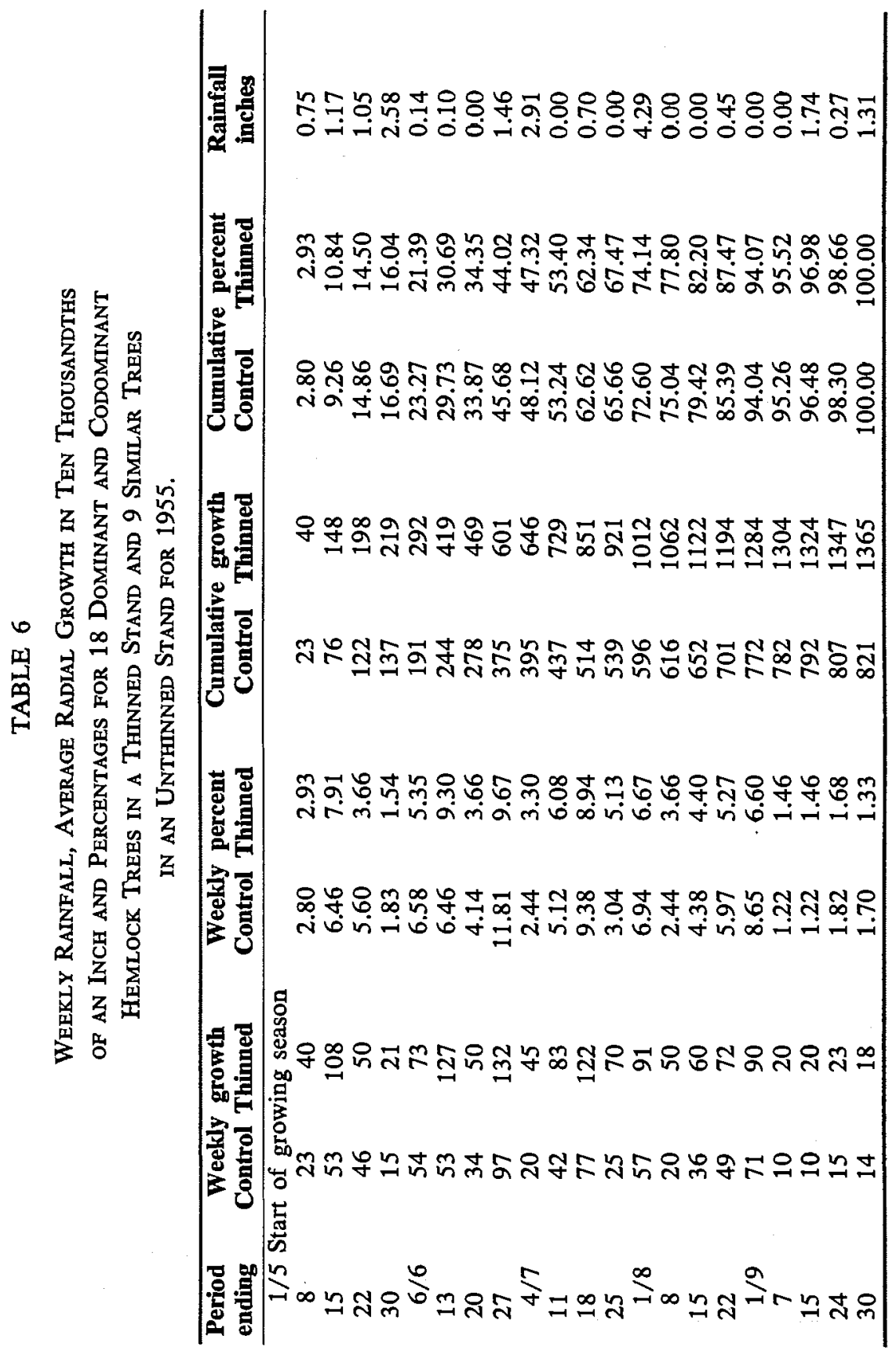


31 (Table 6). Percentage growth followed the same general pattern as in 1954 for both thinned and control trees (Fig. 2). Total radial growth was less than that of 1954, however; the thinned trees averaged 0.1365 inches radial increase in comparison with 0.0821 inches for the controls. This represents a decrease of 18.63 percent in radial growth for the thinned trees and a corresponding decrease of 7.13 percent for the control trees from the 1954 values.

1956. Radial growth commenced about May 1, 1956. The thinned trees continued to grow until October 7 whereas the controls ceased growth about September 30. The control trees completed 95.40 percent of their total growth by August 31 and the thinned trees 96.40 percent (Table 7). The pattern of growth, however, differed from the two previous years (Fig. 3). The percentage growth for the thinned trees during the last week of May and throughout June fell behind that of the control trees so that by the end of June the thinned trees had completed 46.78 percent of their total growth for the season compared with 60.25 percent for the control trees. During the last two weeks in August and the first week of September the control trees consistently showed a decrease in radius and did not show a permanent increase until after September 7. During the same period, growth of the thinned trees was greatly reduced but each tree did show some positive increase in radius. This was a period of very low rainfall and high daily temperatures and the shrinkage of the radii of the control trees

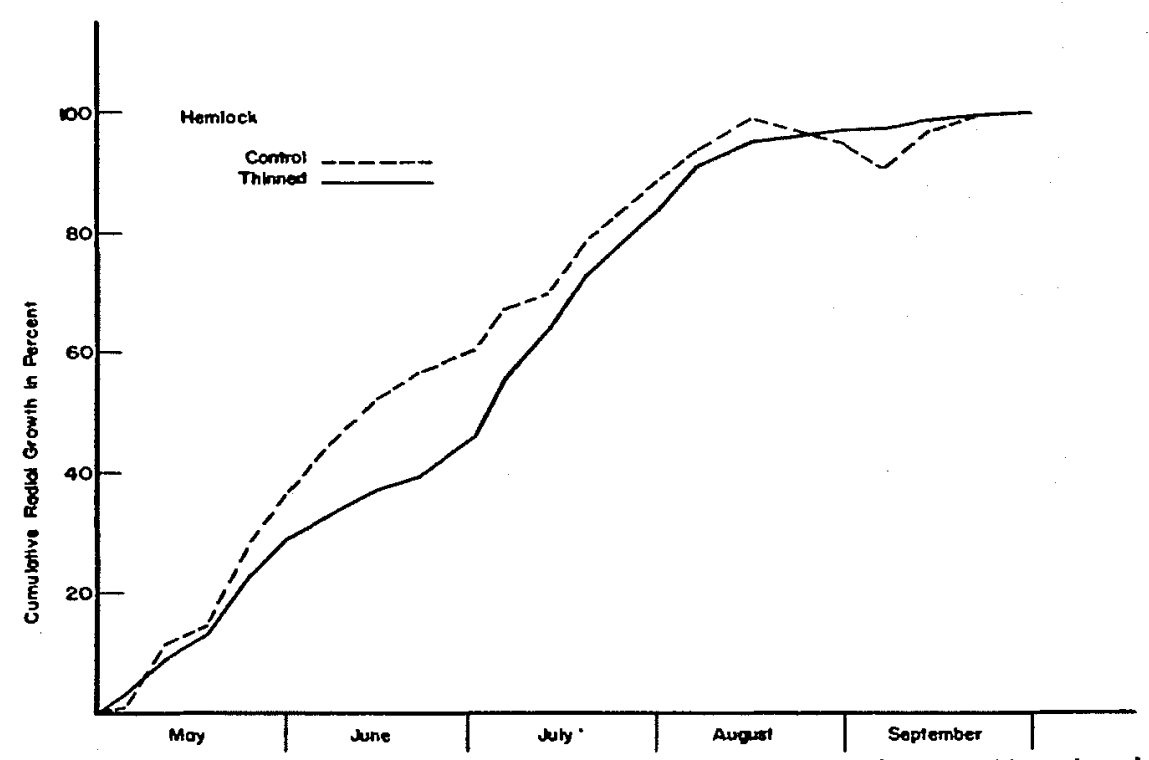

Fig. 3 Cumulative radial growth in percent of totol growth for the thinned and control trees for 1956 . 
JUNE, 1959

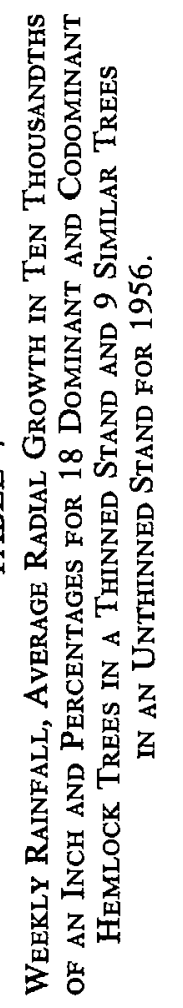

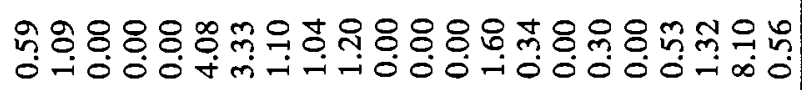

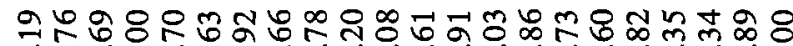
तळ

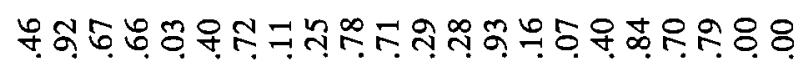

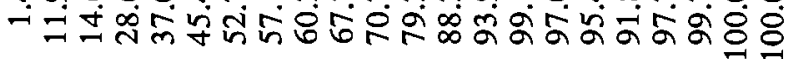

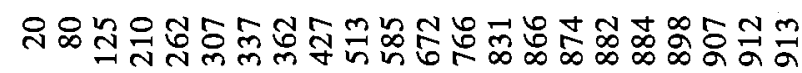

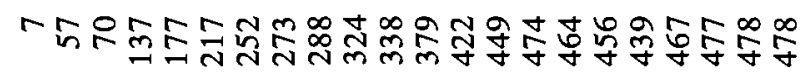

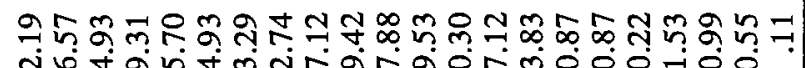

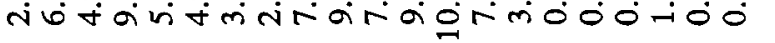

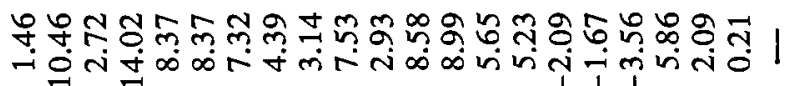
1 ।

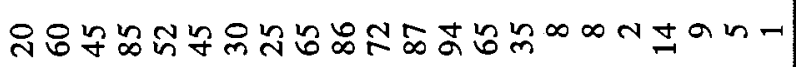
: 
was probably due to excessive dehydration of the stems. Total increase in radius per tree for the season was 0.0913 inches for the thinned trees and 0.0478 inches for the control trees. This represents a decrease of 45.49 percent in radial growth for the thinned trees and 46.15 percent for the control trees as compared with the radial growth for 1954.

\section{Basal-Area Growth}

Basal-area growth was computed from the radial measurements of each tree for monthly periods. Inside-bark diameter measurements at the beginning and end of each month were used in determining basal-area growth for the month. Where a dendrometer reading was not made at the exact end of a month, monthly growth was obtained by interpolation. Table 8 gives the average monthly and the seasonal basal-area growth in square inches per tree for trees on the thinned and control areas for the years 1954, 1955, and 1956. For the year 1954, total growth for the control trees was 1.0598 square inches per tree, and for the thinned trees, 2.3509 square inches. In 1955, total growth for the control trees was 1.0621 square inches per tree and 2.0552 square inches for the thinned trees. This was a slight increase for the control plot over the 1954

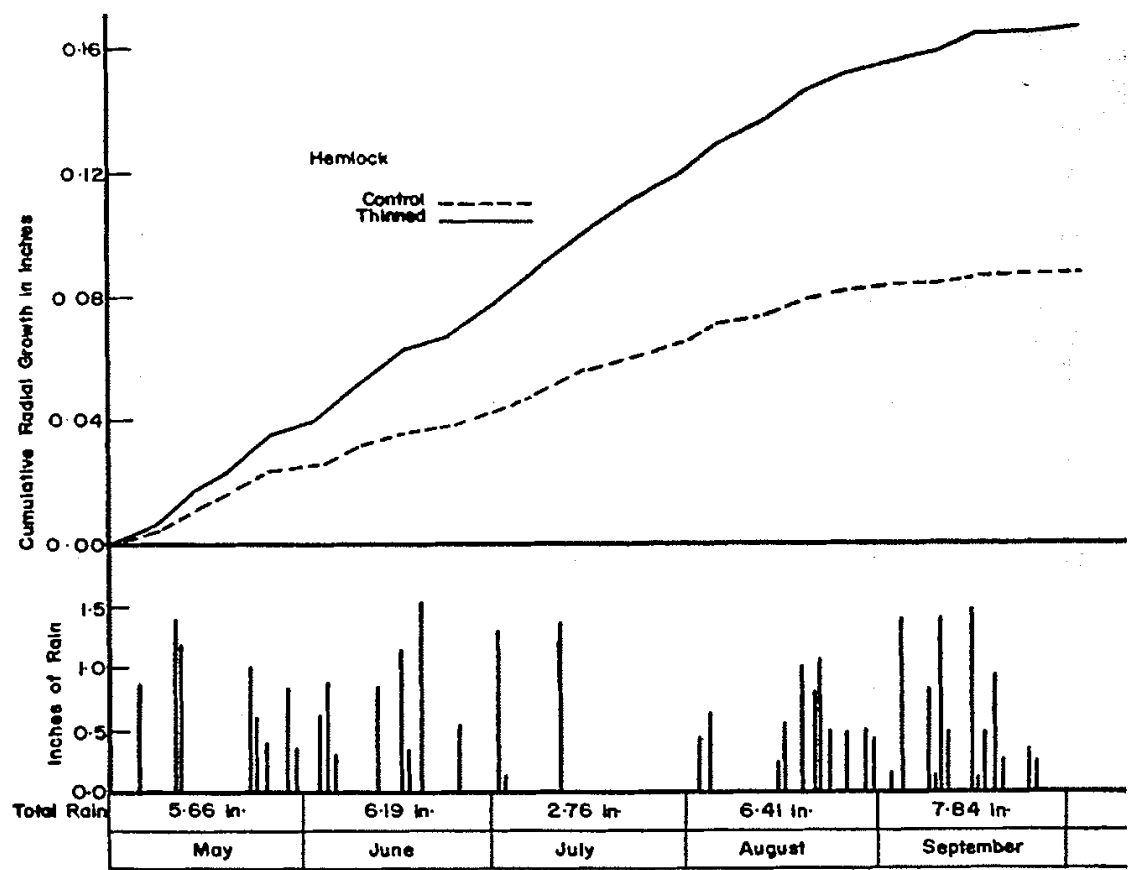

Fig. 4 Cumulative radial growth in inches for the thinned and control trees and distribution of rainfall for 1954 . 


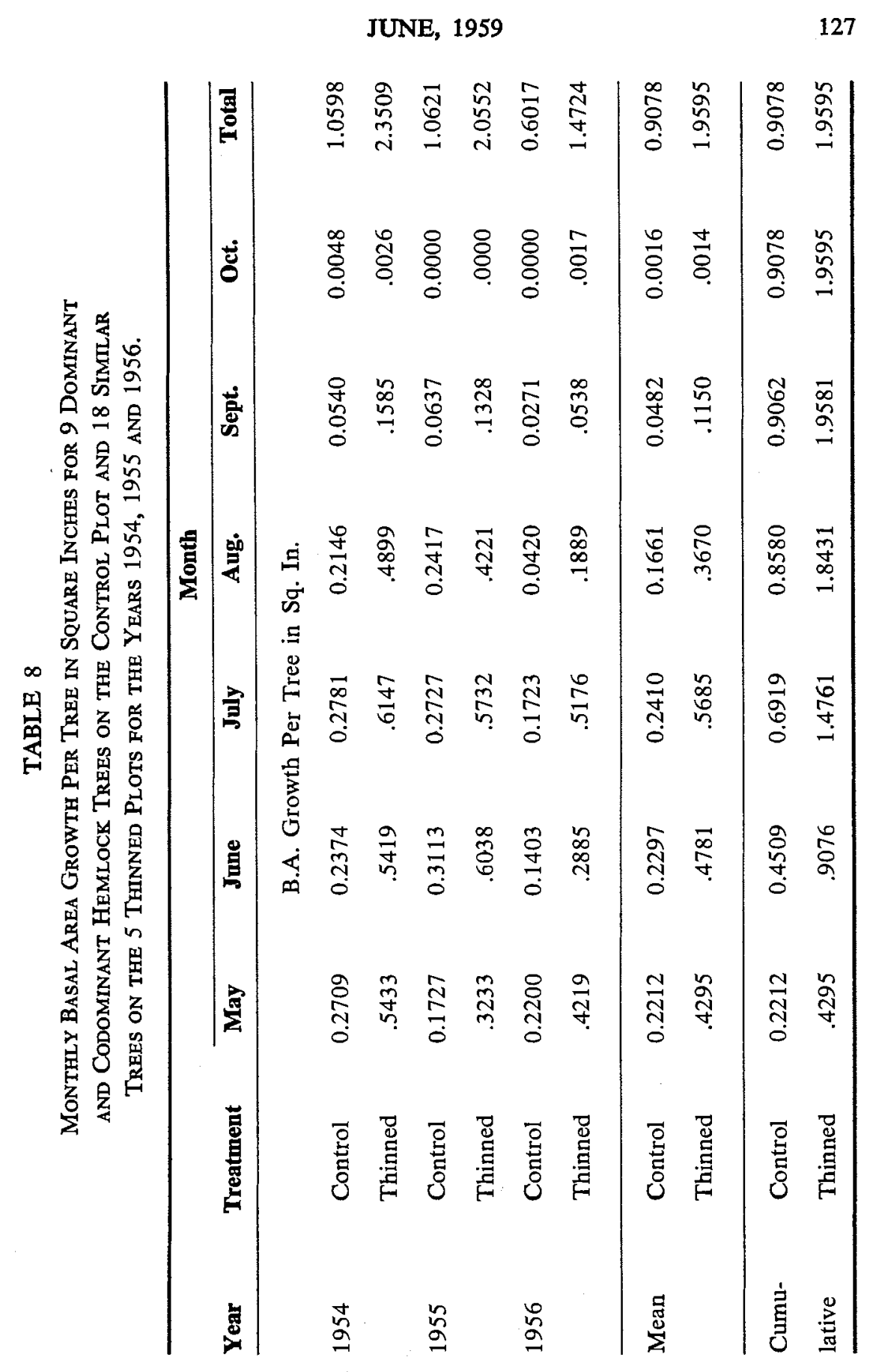


basal-area growth, but a decrease of 12.58 percent for the thinned trees. In 1956 basal-area growth for the control trees was 0.0617 square inches per tree and 1.4724 square inches for the thinned trees. This represented a decrease in basal-area growth of 43.23 percent and 37.37 percent for the control and thinned trees, respectively, as compared with the growth figures for 1954. Average annual basal-area growth per tree for the three years was 0.9078 square inches for the control trees and 1.9595 square inches for the thinned trees; growth in basal-area per tree for the thinned trees was, therefore, more than twice that of the control or unthinned trees (Fig. 7).

Table 9 presents monthly basal-area growth expressed as a percentage of total annual growth for each of the three years.

\section{Climatic Data}

The climatic data for the three years of the study and the averages for the preceding 10-year period are presented in Table 4 . The average annual precipitation for the area is 91.77 inches whereas it was considerably higher for the three years 1954,1955 , and 1956, and averaged 103.10 inches. The average monthly rainfall for the growing season, May to September, inclusive, is 3.62 inches and for the three year period was 4.83 inches. There was, however, considerable fluctuation between individual months. For example, 1.55 inches of rain

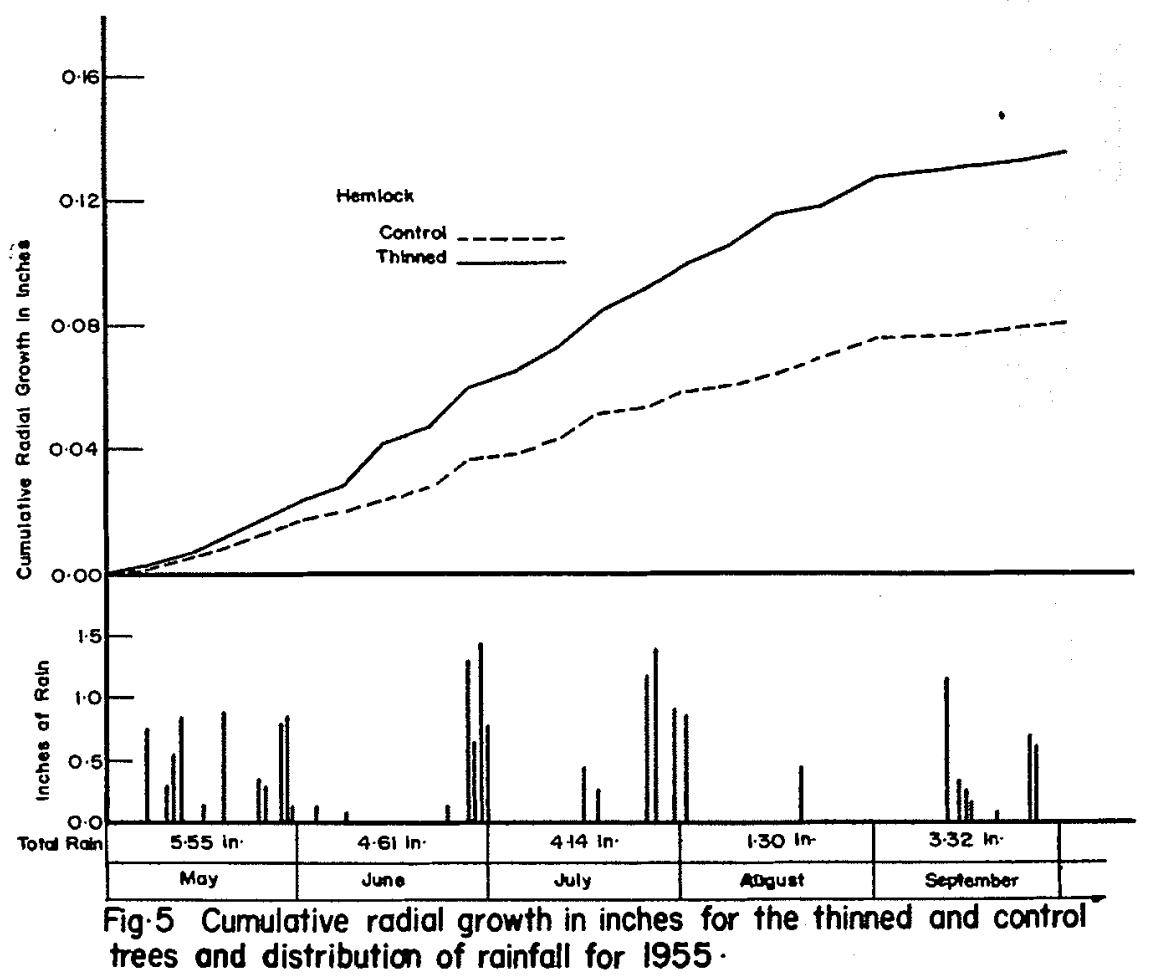


JUNE, 1959

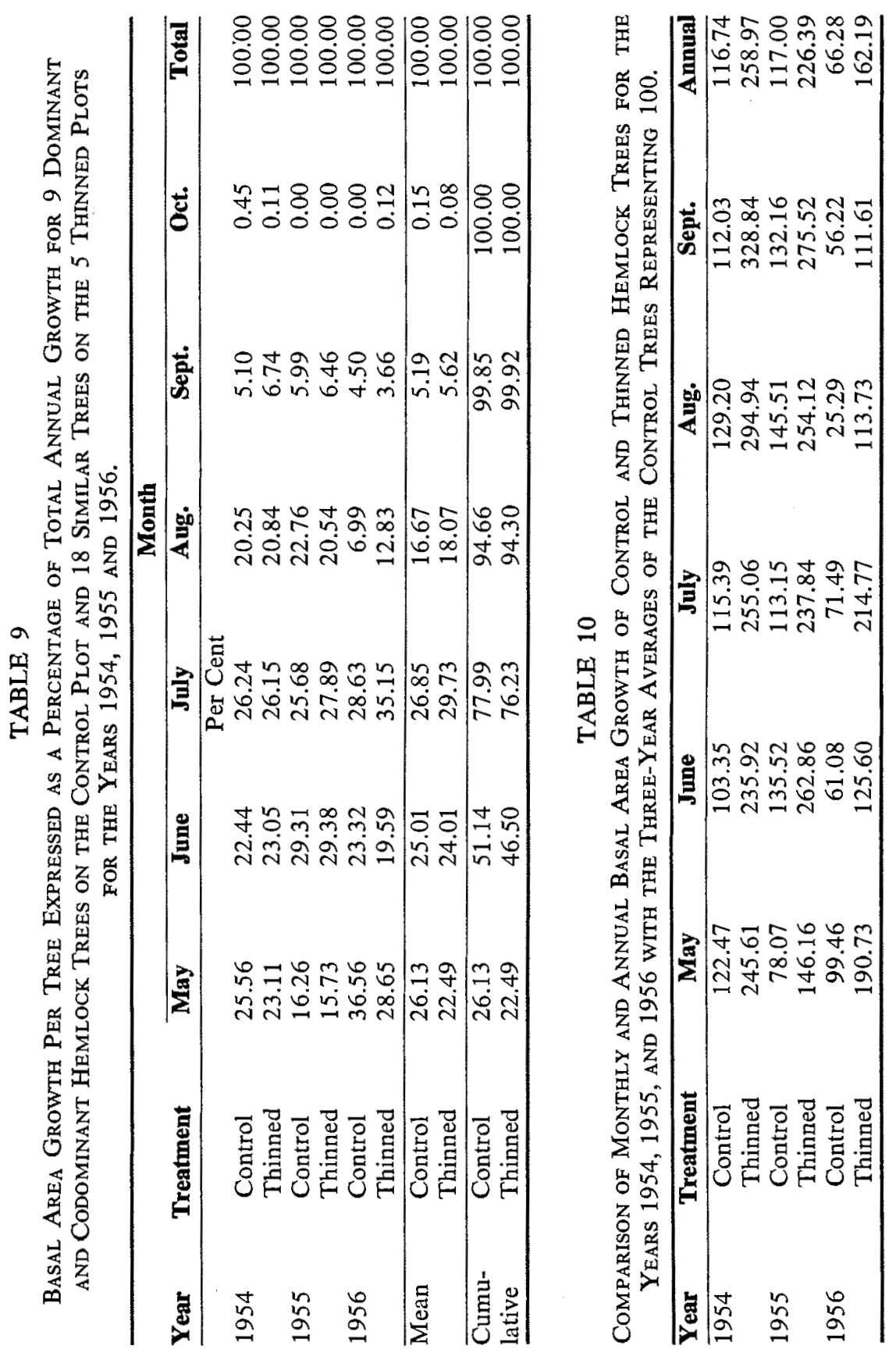


fell in April, 1956, and 1.68 inches in May of the same year, whereas in both 1954 and 1955 for the same two months the rainfall was in excess of 7 and 5 inches. In 1956, the July rainfall was 1.20 inches compared with 2.76 inches in 1954 and 4.14 inches in 1955. In August, 1955, the rainfall was 1.30 inches compared with 6.41 inches in 1954 and 2.24 inches in 1956.

The 10-year average mean monthly temperature for the growing season was 57.80 degrees Fahrenheit, compared with 57.27 degrees for the three-year period. The seasonal mean for 1954 was 56.8 degrees Fahrenheit, for 1955 , 56.8 degrees and for 1956, 59.0 degrees.

The 48-year average for total bright sunshine yearly was 1,399 hours, compared with 1,032 hours for 1954, 1,110 hours for 1955, and 1,404 hours for 1956. For the growing season alone, the 48-year monthly average was 176 hours compared with 123 hours in 1954, 142 hours in 1955, and 185 hours in 1956.

In summary, the three years, 1954, 1955, and 1956, were wetter than the 10-year average. However, 1956 showed considerably more variation from the average than either 1954 or 1955. April and May of 1956 had less rainfall,

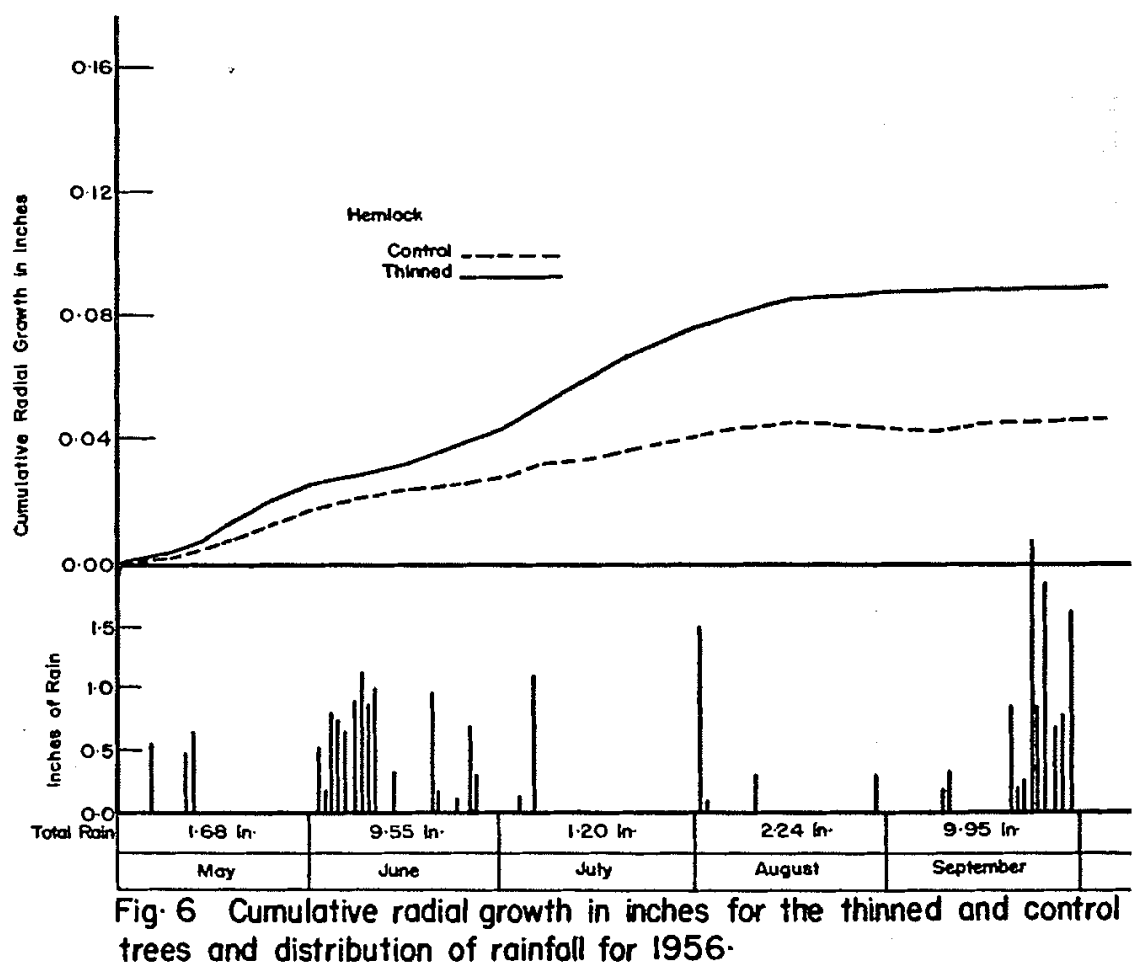


higher temperatures, and as would be expected a greater number of hours of bright sunshine than either 1954 or 1955 and was quite different in these respects from the long-term averages. June of the same year had over twice the average June rainfall-9.55 inches, lower temperatures, and approximately one-half the number of hours of bright sunshine. July and August were drier than the average, with higher temperatures and more sunshine. November 1955 was much colder than the average November; freezing temperatures occurred on November 1 and 2, and on the 14th the temperature reached 5 degrees Fahrenheit.

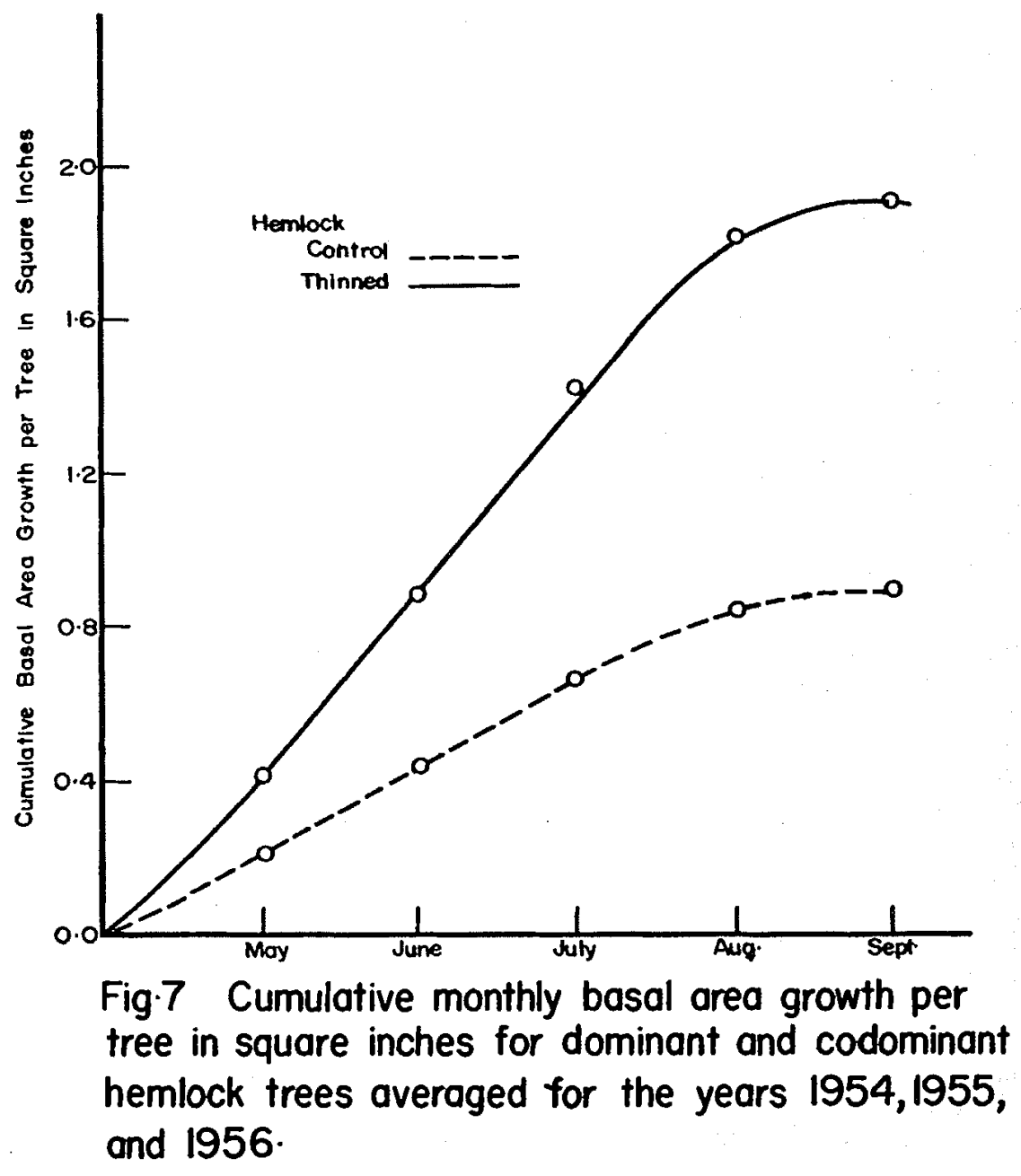




\section{Relation of Climate to Growth}

It was not possible to demonstrate statistically that a significant relationship existed between periodic growth and variations of weather. This may be explained, in part, by the fact that following heavy rain storms the tree stems swelled abnormally due to hydration of the wood and gradually shrank again during periods between storms; as a consequence very little apparent growth was indicated for these between-storm periods, whereas a dendrometer reading taken immediately after a heavy rainstorm indicated apparent excessive growth. Figures 4, 5, and 6 show the distribution of rain and accumulative radial growth for the control and thinned trees for the years 1954, 1955, and 1956.

Examination of the climatic data and the tables for growth indicates a definite relationship between the type of weather and monthly rates of growth. May, 1955, was a cool wet month with only 66 hours of bright sunshine, a mean temperature of 48 degrees Fahrenheit, with a maximum temperature of 65 degrees, and a total of 11 rainy days. Average basal-area growth for the month was 0.1727 square inches per tree for the control trees and 0.3233 square inches for the thinned trees. These figures represent 63.75 percent and 78.50 percent of the growth respectively for the control trees during May of 1954 and 1955, and 59.51 percent and 76.63 percent for the thinned trees for May of the same years. May, 1954 and 1956 were warmer, with considerably more sunshine- 151 and 226 hours respectively-fewer rainy days, and higher temperatures than May, 1955. Basal-area growth for June, 1955, exceeded that of either June, 1954, or 1956, for both control and thinned trees. For June, 1954, basal-area growth of the control trees was 76.26 percent and for June, 1956, only 45.07 percent of the growth for the same month in 1955, whereas for the thinned trees the percentages were 89.75 and 47.78 for June, 1954 and 1956, respectively. June, 1955, was warmer, with higher mean and maximum temperatures, less but ample rainfall, fewer wet days, and a greater number of hours of bright sunshine than either June, 1954 or 1956.

Total growth for 1956 was considerably less than that of either 1954 or 1955, although the year appeared to be a favorable one for growth. The explanation appears to lie in the fact that in the preceding November temperatures were much lower than for any other November on record; freezing temperatures occurred on November 1 and 2, and again during the period of November 11 to 22, with minimum temperatures of 5 degrees Fahrenheit on November 14 and 15 . These abnormally low temperatures in November resulted in considerable frost damage to the trees-damage which became quite noticeable during the spring and early summer of 1956 and resulted in extensive defoliation. On the experimental area itself the main effect of the frost was the death of the leaves of many trees; in the immediate vicinity of the study area, however, the leaders of many Douglas fir, hemlock and western red cedar trees were also killed. Growth in May, 1956 did not appear to have been affected by the frost damage, but the slower growth for the succeeding months may be directly attributed to the extensive defoliation of the trees as a result of the November frosts. Table 10 gives a monthly and annual comparison of basal-area growth for the years 1954, 1955 and 1956. 


\section{Summary of Growth}

In each of the three years, growth of the hemlock trees started during the first week of May and terminated during the last week of September or the first week of October. There was no significant difference between the duration of the period of growth on the control and that on the thinned areas. There was, however, a difference between the pattern of growth for 1954 and that for 1955. In 1954, 25.56 percent of the total growth in basal area occurred in May compared with 16.26 percent in May, 1955; comparable figures for the thinned trees were 23.11 percent and 15.75 percent, respectively. By the end of August, 1954, the control trees had completed 94.49 percent of their basalarea growth and in $1955,94.01$ percent, compared with 93.15 percent and 93.54 percent for the thinned trees for the same periods. The damage caused by the low temperatures of November, 1955, probably resulted in abnormal growth in 1956. For each of the three years under study, the 18 thinned trees grew in basal area more than twice as fast as the 9 control trees. The pattern of percentage radial growth was similar for both control and thinned trees in 1954 and 1955, but they differed somewhat in 1956 . 